\title{
Who owns truth?
}

\section{John Launer}

Two journal articles caught my attention recently, mainly because they offered diametrically opposed views of patients. One was a "Personal view" in the BMJ, entitled "I want to see a consultant". ${ }^{1}$ Written by a surgical specialist registrar from Scotland, it proposed that most requests from patients to see a consultant in a hospital appointment should be "acknowledged but politely rejected". The author, who admitted to seeing such requests as "an insult and a challenge", put forward two different reasons for turning them down. Firstly, such requests can simply be an example of assertiveness and hence an attempt to gain an unfair advantage. Secondly, the writer thought they implied criticism of medical staff below consultant grade, and therefore reduced the professional respect of team members.

The article was an interesting one, since it combined a belief in equity of access with what seemed like an acute sensitivity to actual or imagined slights. I would love to know what the writer will think of his current views when he reads them again in a few years as a seasoned consultant. As some respondents to the article have pointed out, it would also be fascinating to know what his opinion will be once he has escorted a relative to a series of desultory and uncoordinated appointments with five or six different juniors, or when he goes through this as a patient himself.

The contrasting article was a piece of research that appeared in the pages of Quality and Safety in Health Care. It presented an analysis of over 20000 malpractice claims from Swedish patients. ${ }^{2}$ Sweden, like one or two other countries, operates a "no fault" scheme that offers compensation if an independent review by physicians confirms that a patient has suffered harm from a medical error. The analysis showed two striking results. One was that claims arose in only one in 500 discharges. The other was that around a half of all claims were judged to be valid and thus eligible for compensation. The authors concluded that patients'

Correspondence to: Dr John Launer, London Department of Postgraduate Medical Education, Stewart House, 32 Russell Square, London WC1B 5DN, UK; jlauner@londondeanery.ac.uk complaints about the quality of care should be taken very seriously, and offered a unique source of information on preventable errors. In other words, we should welcome complaints as opportunities for learning.

\section{FUNDAMENTAL DIFFERENCE}

In some ways it is very unfair to juxtapose these two unrelated articles. The first was an opinion piece, possibly thrown together in a moment of exasperation, or provoked by a particularly trying set of local circumstances. The second was a measured piece of peer reviewed research, coming from a country with proverbially generous resources. Yet the articles invite comparison because they represent a fundamental difference at a philosophical level in their view of what it means to be a patient, and what the doctor-patient relationship should be about.

In the opinion piece, there is an assumption that the doctor has an a priori right to determine what is really happening, and to decide what should happen next. In the research article there is an acceptance that a patient's story of what has gone wrong is likely to point towards something that we as doctors should amend in ourselves. The view of the world presented is not one where the doctor stands above the patient hierarchically, but one in which doctor and patient should influence each other equally.

In the commercial world, and especially in retail, there is a common mantra in staff training that "the customer is always right". Sometimes the principle is applied disingenuously, and shop assistants are simply taught to smile in order to ensure a sale. In companies with a more thoughtful approach, it signifies a far deeper understanding: that customers are subjects, not objects, and that their wishes, criticisms and even negative comments carry as much validity as anything that company employees may think. It is a view in which staff and customers are seen as connected through a loop of mutual information exchange. Complaints ("this toaster has a design fault") are seen as an immediate call for sympathy and curiosity rather than a personal affront.

\section{ENTRENCHED PATERNALISM}

In medicine, it has been hard to see things in quite this way. Partly this has been because of the social relations that have existed between doctors and most of their patients. Partly it is because of the specific technical expertise that doctors hold. While there has been a move in recent years - and for longer in private medicine-towards a form of consumerism centred around the rhetoric of "choice", this has often been a veneer covering an entrenched paternalism in the way that doctors actually interact with patients. What has been largely missing so far, and what the paper from Sweden represents, is an idea that patients' views of their medical encounters-including or even especially when these encounters go wrong-should be accorded equal status with our own.

The central question here is: who owns truth? Although we pay lip service to being patient centred, most medical encounters are still based implicitly on the notion that the doctor has a correct view of the world to impart, and the patient's proper task is to understand this and to act accordingly. Where dire illnesses and risks are concerned, this model probably makes sense. However, a problem arises whenever we extend this approach to the patient's own subjective experience, and decide that the only possible grounds for differing from us, or for a complaint, must be an aggressive attitude, a difficult personality, or a mental health problem. We then become wedded to our own hypotheses about someone else's behaviour, and incapable of seeing how we have moved away from scientific certainties and into the realm of prejudice.

In the uncomfortable area of personal perceptions, our views should carry no more privilege than anyone else's. Our own ideas may even need to become subordinate to others if we want to understand patients and learn from them. That may be an uncomfortable thought for many doctors, but I doubt if we will get much further into the 21st century before it becomes the norm.

Competing interests: None declared.

Postgrad Med J 2009;85:392.

doi:10.1136/pgmj.2009.083436

\section{REFERENCES}

1. Crampsey DP. "I want to see the consultant". BMJ 2009;338:1136.

2. Pukk-Harenstam K, Ask J, Brommels M, et al. Analysis of 23,364 patient-generated, physicianreviewed malpractice claims from a non-tort, blamefree, national patient insurance system: lessons learned from Sweden. Qual Saf Health Care 2008;17:259-63. 